\begin{tabular}{|l|l|l}
\hline & $\begin{array}{c}\text { Informing Science: } \\
\text { the International Journal of } \\
\text { an Emerging Transdiscipline }\end{array}$ & $\begin{array}{l}\text { An Official Publication } \\
\text { of the Informing Science Institute } \\
\text { InformingScience.org }\end{array}$ \\
\hline
\end{tabular}

Volume 24, 2021

\title{
INFORMING AGILITY IN THE CONTEXT OF ORGANIZATIONAL CHANGES
}

Rimvydas Skyrius*
Mindaugas Krutinis
Svetlana Nemitko
Justina Valentukevičè
Norbert Andžej
Gulbinovič
Marija Sanosianaite
* Corresponding author

ABSTRACT
Vilnius University, Vilnius, Lithuania rimvydas.skyrius@evaf.vu.lt

Vilnius University, Vilnius, Lithuania mindaugas.krutinis@evaf.vu..lt

Vilnius University, Vilnius, Lithuania

Vilnius University, Vilnius, Lithuania

Vilnius University, Vilnius, Lithuania

Vilnius University, Vilnius, Lithuania svetlana@streamline.lt

justina.valentukevice@gmail.com

andzej.gulbinovic@evaf.stud.vu.lt

marija.sanosianaite@evaf.stud.vu.lt

Aim/Purpose

This paper, although conceived earlier than the emergence of COVID-19 pandemic, addresses the problem of informing agility as part of organizational agility that has become a rather important issue for business survival.

Background

While the general issues of business informing, and business intelligence (BI) in particular, have been widely researched, the dynamics of informing, their ability to act in accord with changes in business and preserve the key competencies has not been widely researched. In particular, the research on BI agility is rather scattered, and many issues need to be clarified.

Methodology

A series of in-depth interviews with BI professionals to determine relations between organizational agility and BI agility, and to round up a set of key factors of BI agility.

Contribution

The paper clarifies a candidate set of key factors of BI agility and gives ground for future research in relations with areas like corporate and BI resilience and culture.

Findings

The interview results show the relations between organizational changes, and changes in BI activities. BI has limited potential in recognizing important external changes but can be rather helpful in making decision choices and detecting internal problems. Lack of communication between business and IT

Accepted by Editor Eli Cohen | Received: February 17, 2021 | Revised: April 30, May 15, 2021 | Accepted: May 16, 2021.

Cite as: R. Skyrius, M. Krutinis, S. Nemitko, J. Valentukevičè, N. A. Gulbinovič, \& M. Sanosianaitè. (2021). Informing agility in the context of organizational changes. Informing Science: The International Journal of an Emerging Transdiscipline, 24, 19-30. https://doi.org/10.28945/4789

(CC BY-NC 4.0) This article is licensed to you under a Creative Commons Attribution-NonCommercial 4.0 International License. When you copy and redistribute this paper in full or in part, you need to provide proper attribution to it to ensure that others can later locate this work (and to ensure that others do not accuse you of plagiarism). You may (and we encourage you to) adapt, remix, transform, and build upon the material for any non-commercial purposes. This license does not permit you to use this material for commercial purposes. 
people, existence of data silos and shadow BI, and general inadequacy of organizational and BI culture are the key factors impairing BI agility.

Recommendations There are practical issues around BI agility that need solving, like the reasonfor Practitioners able coverage of standards or creation of a dedicated unit to care about BI potential.

Recommendations The research is still in its starting phase, but additional interesting directions for Researchers start to emerge, like relations between BI agility, resilience and corporate agility, or the role of informing culture and BI culture for BI agility issues.

Impact on Society Agile business, especially in times of global shocks like COVID-19, loses less value and has more chances to survive.

Future Research Most likely this will be focused on the relations between BI agility, resilience, and corporate agility, and the role of informing culture and BI culture for BI agility issues.

Keywords organizational agility, business intelligence agility

\section{INTRODUCTION}

The usual terms describing the current business environment - "fast", "turbulent", "dynamic" - have been coupled to necessity to face changes and prepare for them. The orientation towards permanent changes has supported the spread of the notions of corporate agility, resilience and ability to survive. The arrival of COVID-19 pandemic, however, has put a sudden and harsh test to such qualities. While the conditions of activity under the pandemic are rather different for different lines of business, no business activity remains untouched.

The pandemic is performing a severe test on maturity, agility, and resilience of any organized activity. The function of corporate IT, information systems, and business intelligence (BI) in particular will be affected as well. Opulent analytics have to adapt to new conditions or give way to blunt estimates and insights on mere survival. External context suddenly is extremely hard to forecast and to develop scenarios. Military-grade informing measures are required to maintain control over situations with fast and flexible decisions, direction and rearrangement of resources, and subsequent action to achieve results with minimum delay.

It should be noted here that many BI studies, performed in less turbulent times, have been oriented towards the growth of operational measures like user satisfaction, BI value, or profitability as a sought-after result or dependent variable (see, e.g., Talaoui, \& Kohtamaki, 2020). Such studies often do not discern between measured short-term gains and long-term effects that may positively or negatively influence the agility and vitality of an organization. We make an assumption here that agile informing is one of the key factors of agile behavior of an organization, enabling appropriate and timely action. While these considerations seem rather obvious, the area of informing agility, and especially BI agility, is rather under-researched. So the current paper focuses on agility (and resilience) of business intelligence and analytics. Without this discussion, BI has to adapt and evolve anyway, but we believe that a set of common features or factors of agility can be defined that would provide guidance for maintaining BI being more agile and less fragile and rigid.

In general, agility is a term that defines fast and flexible action - the opposite to inertia and rigidity. Being currently on the rise, the notion of agility is applied to many different areas - agile organization, agile business, agile software development, agile process, and so on. In any of these cases, agility is hardly possible without awareness and fast decisions - features that are based on the use of information and informing process. Zimmer et al. (2012) state that agility "is understood as the ability to 
react to unforeseen or volatile requirements regarding the functionality or the content of a BI solution in a given time frame." Conboy, and Fitzgerald (2004) define agility as "the continual readiness of an entity to ... embrace change through high quality, simplistic, economical components and relationships with its environment." As this paper discusses the issues of business intelligence (BI) agility, for its purposes the issues around BI agility can be divided into two interrelated areas:

- The role of informing and BI in supporting organizational agility; and

- the agility of BI function itself.

Several examples of situations requiring BI agility:

- Flexible adaption to new information sources;

- Flexible adaption to new BI platform, especially when there is a need to transfer accumulated skills. There always are innovations that significantly differ from what's currently in use;

- Flexible adaption to new informing requirements: internal - integration of data and information that has not been done before - or external - e.g., new disclosure requirements;

- Adaptation to changes in business models, especially interconnected partnerships.

One more important feature of organizations, often mentioned together with agility, is resilience, the relevance of which has grown with the current pandemic. Both agility and resilience are related in a sense that they are intended to handle disruptive forces, deal with changes, and overcome uncertainties. However, there are differences: agility deals with both threats and opportunities, while resilience focuses more on large-scale problems and abilities to maintain the significant or maximum share of potential or capacity. Agility mostly means fast and flexible action driven by current results, while resilience aims to overcome hard times with minimum losses. Although resilience is not a subject of this paper, it is a potentially rather interesting issue both for organizations (this direction is currently being actively researched) and informing activities (still under-researched), and most likely will be considered in the future.

\section{RELATED WORK}

In literature discussing organizational agility and its features, one of the key supporting roles in dynamic business environment is adequate informing (Laval et al., 2018). According to Zimmer et al. (2012), BI is seen as a set of resources or a collection of capabilities that need to be constantly rearranged and reconfigured for sustaining adequate informing and analytic competence. Cyert, and March (1963), discussing organizational learning in the early years of business informing, have argued that a firm learning from its experience leverages rules, routines, and procedures intended to respond to external shocks, and by doing this strengthens organization agility and adaption to the environment changes. Discussing the implications of dynamic capability theory for BI, Meredith et al. (2012) differentiate between moderate-velocity context and high-velocity context. In moderate-velocity case, analyses may be complex, but they are executed in a predictable path. For high-velocity cases, uncertainty is more common and, therefore, more flexible and an evolutionary approach is required. Another interesting point made by Meredith et al. (2012) is the analysis of two positions, vendor literature and academic research, where authors justifiably point out that vendors concentrate on data engineering to support faster and better decisions without explaining how faster decisions are better. In addition to this, vendors mostly ignore the role of external information that is often of prime importance in transformational situations. Reeves and Whitaker (2020) discuss organizational resilience and describe its focus around the unknown, changeable, unpredictable, and improbable - features that in other works are largely prescribed for agility to cope with. There are numerous works that point out the weaknesses of rigid and inflexible organizations and their practices - institutionalized procedural order that worked in its own time, but eventually became rigid and inflexible. An opposite approach - the ability to evolve through trial and error - has been pointed out by Reeves and Whitaker (2020), who bring up an important point of adopting constant change and experimentation as the 
default, deeming iterative adjustment far less risky than massive one-time changes. Discussing dynamic capabilities, Zahra et al. (2006) have noted, "Managers do not, and probably should not, create 'once-and-for-all' solutions or routines for their operations but continually reconfigure or revise the capabilities they have developed. ... The new routines form the foundation of firms' knowledge bases." However, old routines remain in some form of experience collections, although as valid competences they have lost their usefulness. Such experience collections may form a sort of timeline or time series of competence changes and may be useful in forecasts for new competences.

Although not abundant, there is a certain volume of published research dedicated to the issues of informing agility and its possible impact on organization. Knabke and Olbrich (2018) have presented the results of research on factors influencing BI agility and have pointed out BI adoption for business operations and market understanding having significant impact on BI agility. Baars and Zimmer (2013) argue that BI solution that is seen agile from one business line perspective can have negative impact on agility of enterprise-wide BI and suggest splitting of BI agility concept based on subject of agility (content, function, scale) and architectural layers. Different perspective of BI agility concept is presented in the article by Skyrius and Valentukevice (2020), where authors stress the importance of managerial and especially cultural factors in building up agility competences at three levels: organizational, informing, and BI. Laval et al. (2018) proposed to measure informing agility as the key performance indicator for an existing enterprise information system and noted that very few research works focus on IS agility and its measure. Simchi-Levi et al. (2014) have proposed a model of timeto-recovery in situations with unexpected shocks. Instead of attempting to quantify the likelihood of events with high risk and low probability, the authors suggest identifying the most important exposures and developing risk-management plans to mitigate them. Blay et al. (2020) developed an information resilience framework, based on several persistent resilience dimensions like adaptability, business continuity, coping ability, awareness and preparedness, and several antecedents of resilience redundancy, flexibility, promoting innovation and valuing variety, monitoring, learning from the past, resilient culture. The culture element stands out in many sources pointing out that agile is more a culture than a process (Appelo, 2010; Denning, 2010; Hesselberg, 2019; Kulak \& Li, 2017; Spayd, 2010).

Summing up, agility may be defined as the feature of BI reflecting the readiness to cope with the dynamics of business and supporting competencies to navigate and survive in complex, dynamic, and unpredictable contexts.

The results of literature analysis, and the resulting positioning of BI agility, have prompted the subsequent research activities. Several issues deserving consideration have come out. Firstly, BI agility, and agility in general, is a vague concept, although several features, like flexibility, collaboration, awareness, and ability to learn, are common to most existing research on the subject. Secondly, technical agility issues intertwine with managerial and organizational issues, creating a complex informing environment that is more a culture than a process or technical excellence. The existence of these issues has guided the choice of research method, presented in more detail in the following section.

\section{RESEARCH METHODOLOGY}

\section{RESEARCH PHILOSOPHYAND METHOD}

This qualitative research was performed following a paradigm of interpretivism. Since the phenomena is under-researched and complex, the study of meanings to research participants can create new, richer understandings of organizational realities (Saunders et al., 2016). We assume the individual, indepth, semi-structured interview to be the most effective method of gathering information for our research because it is flexible, accessible, intelligible, and provides the opportunity for discussion, through which complexities are explained and new topics emerge (Qu, \& Dumay, 2011). 
In order to be able to explore a phenomenon in sufficient detail, the duration of each interview was between 1 and 2 hours. The interview guide, with the set of 14 pre-designed questions ordered to follow a logical progression based upon the objectives of the study, was prepared and used during interviews but since the interview format was semi-structured some questions were rephrased, reordered, added, or skipped based on the interviewee's background and responses. The interviews were conducted on a one-to-one basis. Due to Covid-19 related epidemiologic situation, most of the interviews were conducted via remote video communication service such as Microsoft Teams. Interviews were recorded and transcribed.

For triangulation purposes the interviews were conducted by 5 researchers. This allowed to ensure quality of the data by addressing the risk of researcher bias.

\section{SAMPLING}

We followed the judgmental sampling approach in selecting respondents to ensure a relevant representation of the researched phenomena. In total ten interviews were conducted with a sample of informants in BI specialists or managers positions from medium to large-sized firms and BI experts from firms providing BI services to medium-large size clients. All interviewed respondents were from local or international companies with operations in Lithuania.

Due to the complexity of analyzed phenomena, the homogeneity of the population under consideration and the contact time spent on each individual respondent, we believe that sample size of 10 is representative to generate a valid research finding. However, the research group plans to execute several additional interviews with the aim to move closer to the data saturation point and observe more information or themes in the data from completion of additional interviews (Guest et al., 2006).

\section{DATA ANALYSIS}

The general inductive approach was applied to condense raw textual data into a summary format, to establish the links between research objectives and findings derived from the data, and to describe the most important themes (Thomas, 2006). This approach was selected as it allows reliable and valid research findings to emerge from the themes inherent in raw data by applying simple procedures for analyzing qualitative data.

The transcripts were read and analyzed by 2 members of the research team with an output of identified themes most relevant to research objectives.

\section{INTERVIEW FINDINGS}

The structure of the interview has targeted the issues of organizational changes and the role of BI in the process, followed by changes in BI and perceived BI agility and factors supporting or limiting agility.

\section{RECENT CHANGES FOR ORGANIZATIONS}

The respondents have been asked to indicate the changes, experienced over the last three years by their organizations. The named changes are rather varied and do not allow for any generalization. However, the two important events having happened lately are mentioned by everyone - COVID-19 and Brexit - because they have affected virtually any business. As a consequence of COVID-19, many retailers have established or reinforced their e-commerce platforms. Many employees, especially the ones working with information or digital products and services, had to switch to working from home. Some sample responses:

"Brexit has affected the import-export oriented trade and retail companies. What-if' scenarios had to be developed to estimate the changes in customs taxes and see how competitiveness would be affected." 
Informing Agility in the Context of Organizational Changes

"In some travel-related sectors like aviation and airports, business has experienced serious setbacks, tightening belts and reconsidering investments. Many layoffs have been made."

"All of our customers (the company performs IT technical support) bad to switch to working from home because of the pandemic. Although the move was executed smoothly, the number of problems and volumes of work have increased."

"The pandemic has forced the digitalization and virtualization of work processes. More work emerged for call centers, and an e-commerce channel had been established."

\section{BI ROLE IN OR GANIZATIONAL CHANGES}

The role of $\mathrm{BI}$ in detecting and recognizing organizational changes is, in many cases, undefined and unclear. Meanwhile, at the more simple level of informing, the role of ERP systems is quite clear, and activity seriously suffers if these systems go out of service. The dependency upon BI is not so clear; on the other hand, managers and decision makers at all management levels want to be well-informed. One of the most important reasons for this contradiction is an obvious absence of feedback between the business and BI specialists, leading to misunderstandings and disappointments.

$\mathrm{BI}$ is hardly able to detect important external changes like Brexit or COVID-19. At the same time, BI is recognized as important for monitoring important internal signals. As well, BI, having incorporated the tools and techniques of decision support, assists in evaluating scenarios or alternatives in making decisions. Several sample responses:

"In reality, it is more the case of business needs directing BI, and less the case of BI showing emerging problems or opportunities in advance. BI has a range of tools (trend estimation, portfolio analysis), but the management hardly uses them, and carries on analysis in Excel. ... The BI had created interactive graphs and tools, but nobody used them. The main reasons for this are the lack of intelligence culture, and significant workloads that prevent wider perspectives."

"The data is directed towards data-based decisions. BI specialists are lacking feedback on how business use data for decision making."

"The BI system has helped noticing some transaction-related customer trends, like a relation between money transfer delay and transaction payment - clients prefer to wait for 3 days to avoid paying for the transaction."

"The BI system is used to base business cases and validate hypotheses before making decisions."

'In practice I haven't seen such situations that BI would be telling what changes in organization are needed. Most often human insights are being supported by data from BI. For example, for one of our clients we have made forecast model that allowed to evaluate what cost cuts are required in order to survive challenging period of pandemic."

\section{CHANGES IN BI}

As stated before, organizational changes initiate important changes in BI system. Such changes mostly relate to data layer, and the interviewed specialists report cases of changing data structures, creating data warehouses, or opening data silos. There is a noticeable growth of data lake projects in larger organizations, intended to accumulate assorted data from various sources in different formats in a loosely organized collection.

Serious changes in BI have been introduced by the advent of self-service, user-friendly software Qlik, PowerBI; this is seen as a countermeasure for Excelization - a term used for the ubiquitous use of Excel in assorted analytical and intelligence activities and labeled by most sources as "shadow BI". Several sample responses:

"One of the most complicated issues in BI changes is to estimate the impact of changes in client DB to other areas." 
"One of the important changes in BI over the last three years has been the creation of ODL (Operational Data Lake), where data from many systems is collected. ODL is a base for data science models like churn identification or AML (Anti-Money Laundering) models, using internal and external data."

"The creation of data warehouse made creation of static reports a lot easier. Previously, reports have been created by copy-pasting from ERP to Excel, and currently reports are made in real time from updated data. Data warehouse has created substantial value and saved considerable human efforts."

"ABC (Activity-Based Costing) naturally joins data from data silos. But other analytics do not join data from, e.g., commerce and logistics. No one has raised such need; commerce does not care how much merchandise delivery is costing (logistics data). This may be reasoned by the lack of intelligence culture, or by the fact that data analysts did not 'sell' the idea of wider analytical context."

"Most of our clients initiate changes in BI as a consequence of organizational changes such as new business area, new structure, new software as a data source. In most cases BI changes are being done together with organizational change or even before that. I can state that Pareto principle works here as $80 \%$ of changes are being planned and the rest are unexpected ones when BI system was forgotten changing something else."

"Any organizational change can affect and disrupt BI. The implementation of new billing process had severe impact on BI, some data was missing, and many parts needed to be rebuilt."

\section{PROBLEMS UPDATING BI}

Changes in $\mathrm{BI}$, intended to provide more insight potential, permanently lead to managerial problems - ownership, responsibility, motivation, data silos. Many BI systems appear rather inertial when having to face changes, and miscommunication only compounds the problem. Some typical responses:

"The merger of 2 organizations has created the need to join 2 data warehouses. ... Poor sponsoring from company management; did not understand what is being done; large investments have been questioned. Emergence of scope creep; lack of architectural vision. ... Friction between data analysts and data engineering because of figures mismatch. Legacy warehouse contained hardcode. Black box problems started to emerge. Reverse engineering discovered many hardcode locations in legacy warehouse."

"When after a merger migrating from old data warehouse ETL to new data warehouse ETL, no one wanted to accept responsibility. An ownership problem emerged. Business transformations (as a result of merger) bave shown an exaggerated focus on organizational silos, products and processes, and not being customer-centric. There appeared to be 150 systems containing client data."

"BI agility is impaired by technical debt and legacy systems - large old systems that are widely used and hard to replace. Such changes require substantial investment and time."

"Data storage in silo models; there's no scalable data model to encompass the entire activity."

"There's no BICC (business intelligence competency center), BI is performed against separate queries and chaotically. In a working day there's no time for general analytics. There's a lack of understanding what the others

are doing; everyone is in their own bubble; there's no understanding and need to understand the business process in general. No connecting join."

\section{LOW BI AGILITY CONSEQUENCES}

As a result of low BI agility, there is a general drop of confidence in BI, and an overall doubt in BI's role emerges. The spread of shadow BI brings the risks of unmanaged analytic activities, potential errors, and growing animosity between business activities and IT, as the responses show:

"BI agility is an ability to add a data column in $X$ hours. The later it is done, the more complicated it gets to manage, because data are volatile, and delay moves analytics to shadow BI." 
Informing Agility in the Context of Organizational Changes

"Product-based systems are oriented towards the product, not the customer. This is changing to have a better understanding of a customer journey, but obsolete BI technology may slow down the understanding of this journey."

"If a BI project has a wider scope, it often gets stuck because of other teams, and mostly the centralized ones. ... Lack of system agnostic data model."

"The intelligence vision gets stuck on several uncorrelated parameters, and important changes in activity may be missed."

"If required changes in BI are slow, BI system is circumvented, and shadow BI is used. Later, it becomes rather hard to find roots, and this creates mistrust in BI."

\section{AGILITY GROWTH}

Giving the users more control over the changes in BI appears to be one of the leading driving factors behind BI agility. The creation of a dedicated team or unit to handle changes is another solution to boost BI agility. The issue of a reasonable set of rules and standards comes up;;"reasonable" here meaning not too wide to avoid overregulation and support flexibility and not too narrow to avoid contradictions and chaos. It also appears that the two parts of BI - source data part (data and information collections) and functional part (reporting, queries, analytics, modeling etc.) - have uneven agility potential, the functional part being more agile. This may be explained by the more stable nature of data infrastructure that is more acceptable to standards. However, there appears to be a downside to this - in data infrastructure any more serious shakeup is significantly more painful if compared to the functional part. Several responses:

"The decentralization helps to increase the speed of changes. However, in order to ensure common architecture, certain guidelines and rules must be introduced to avoid duplication and discrepancies."

"The most effective way to increase BI agility is to allow the user to lead BI dynamics. Naturally, such approach requires more human resources and is more expensive."

"It is difficult to manage situation due to organizational BI maturity and culture. To increase BI competences, BI center of excellence was established, although they are not responsible for data, and it is a challenge to make sure that business takes ownership of data."

"Unified glossary is the key element, as it should be clear what is called what in the organization."

"If BI activities are not considered and involved during the planning of organizational changes, this might lead to drastic changes in BI. But if BI architects are involved early, then it could be expected to maintain what already exists, and add new content by evaluation if changes are related to old data models or require completely new ones."

"One of the implemented solutions to improve agility was a new team dedicated for implementation of smaller BI changes. This has improved throughput. One more team focuses on larger changes in integrations. As well, data governance board has been established, where all needs for BI are being evaluated and prioritized, and only then they enter the backlog for implementation."

\section{OTHER FACTORS OF BI AGILITY}

Among the managerial, organizational, and human factors, the importance of cultural factors comes up throughout the answers. This also underscores a point that purely managerial instruments like orders or rules do not lead to good results. The development of culture that is supportive to agile competencies cannot be effected by a decree - it is a lengthy and careful process of applying indirect factors-catalysts. 
"The culture issue comes up. The cultural differences between business and IT are visible as one side is oriented towards frequent and fast changes, while the other one is concerned about stability and ensuring that systems do not crash."

"Organization has shifted from being technology-oriented to people-oriented. Not all changes center on technologies; maybe changes are required for culture and people mindset."

"The involvement of business into BI development is an indispensable condition for success. Even the technologically best BI solutions might fail due to the lack of trust, mismatch with business requirements and insufficient collaboration in developing BI."

"The effort to build BI culture and initiative from the top management are important for BI agility. The other factors are trainings, presentations to the end users and availability of user-friendly tools."

"It is not sufficient to have one professional analyst who analyses and shares insights. The analyst could drive analytics culture but not all analysis in business."

To summarize, the interview results, although rather varied, demonstrate several common traits:

- Whatever changes the organization encounters, informing processes, information systems, and BI activities are affected. This is an obvious statement, but very often these changes test the vitality and preparedness of the informing environment. Some of such changes are unexpected and sudden (e.g., COVID-19 pandemic), some are expected and allow preparation (e.g., Brexit), and all of them may seriously disrupt BI activities.

- BI has limited potential to assist the management in recognizing important changes in the external environment. Regarding internal processes, $\mathrm{BI}$ is potentially important to detect problems in early stage, but much less so in external environment.

- Regarding BI technology resources, the changes at data level are painful and require substantial effort. However, some of those changes may be foreseen, allowing better planning. The existence of data silos remains a key problem.

- There is a serious lack of communication between business and IT people, and this lack complicates the BI preparedness for changes, as well as the overall quality of BI services. As a result, problems like shadow BI and hardcode use start multiplying. An establishment of a dedicated organizational unit to oversee the above issues is seen as a significant help.

- Cultural differences between business and IT, as well as rigid overall organizational culture, are an important limiting factor for organizational and BI agility. On the other hand, the importance of culture, both organizational and informing, is more and more recognized and receives growing attention.

\section{CONCLUSIONS}

Although the interviews have shown a rather scattered picture of BI agility issues, the obvious relation between organizational and BI agility has proved to cover all kinds of informing activities. Given the importance of effective informing for good management, this is hardly surprising. However, the agility of technical issues is clearly giving way to the organizational, managerial, and human issues. Several groups of factors affecting BI agility have been identified, where the most prominent factors are business and IT communication, user involvement, BI reinforcement by creating dedicated organizational units, and development of BI culture. The closing statement for this paper may be as follows: agile informing is one of the key factors in organizational agility and resilience, as confirmed by many sources; because of this importance it deserves more research attention than has been assigned until now. This research has rounded up an initial set of factors supporting informing agility. The authors are aware of the limitations of the presented study, regarding both the method (qualitative interview) and the sample (a set of BI professionals or business users). Further research directions are 
planned towards a more systematic view of the set of these factors, as well as a subsequent development of quantitative survey for empirical testing of agility factors.

\section{REFERENCES}

Appelo, J. (2010). Management 3.0: Leading agile developers, developing agile leaders. Pearson Education.

Baars, H., \& Zimmer, M. (2013). A classification for business intelligence agility indicators. Proceedings of European Conference on Information Systems, Utrecht, 163.

Blay, K. B., Yeomans, S., Demian, P., \& Murguia, D. (2020). The information resilience framework: Vulnerabilities, capabilities, and requirements. ACM Journal of Data and Information Quality, 12(3), 1-25. https://doi.org/10.1145/3388786

Conboy, K., \& Fitzgerald, B. (2004). Toward a conceptual framework of agile methods: A study of agility in different disciplines. WISER 2004 - ACM workshop on interdisciplinary software engineering research, 37-44. https://doi.org/10.1145/1029997.1030005

Cyert, R. M., \& March, J. G. (1963). A behavioral theory of the firm. Prentice Hall.

Denning, S. (2010). The leader's guide to radical management: Reinventing the workplace for the 21st century. Jossey-Bass.

Guest, G., Bunce, A., \& Johnson, L. (2006). How many interviews are enough? An experiment with data saturation and variability. Field Methods, 18(1), 59-82. http://dx.doi.org/10.1177/1525822X05279903

Hesselberg, J. (2019). Unlocking agility: An insider's guide to agile enterprise transformation. Addison-Wesley.

Knabke, T., \& Olbrich, S. (2018). Building novel capabilities to enable business intelligence agility: Results from a quantitative study. Information Systems and e-Business Management, 16(4), 493-546. https://doi.org/10.1007/s10257-017-0361-z

Kulak, D., \& Li, H. (2017). The journey to enterprise agility: Systems thinking and organizational legacy. Springer.

Laval, J., Cherifi, C., \& Cheutet, V. (2018). Towards the measurement of enterprise information systems agility to support EIS improving projects. International Journal of Agile Systems and Management, 11(3), 222-246. https://doi.org/10.1504/IJASM.2018.10015581

Meredith, R., Remington, S., O’Donnell, P., \& Sharma, N. (2012). Organizational transformation through business intelligence: Theory, the vendor perspective and a research agenda. Journal of Decision Systems, 21, 187201. https://doi.org/10.1080/12460125.2012.731218

Qu, S., \& Dumay, J. (2011). The qualitative research interview. Qualitative Research in Accounting \& Management, 8(3), 238-264. https://doi.org/10.1108/11766091111162070

Reeves, M., \& Whitaker, K. (2020). A guide to building a more resilient business. Harvard Business Review, July 2, 2020. https://hbr.org/2020/07/a-guide-to-building-a-more-resilient-business

Saunders, M., Lewis, P., \& Thornhill, A. (2016). Research methods for business students (7th ed.). Pearson Education.

Simchi-Levi, D., Schmidt, W., \& Wei, Y. (2014). From superstorms to factory fires, managing unpredictable supply-chain disruptions. Harvard Business Review, 92. https://hbr.org/2014/01/from-superstorms-to-factory-fires-managing-unpredictable-supply-chain-distuptions

Skyrius, V., \& Valentukevičè, J. (2020). Business intelligence agility, informing agility and organizational agility: Research agenda. Informacijos mokslai, 90, 8-25. https://doi.org/10.15388/Im.2020.90.47

Spayd, M. (2010, July 6). Agile \& culture: The results. http://www.collectiveedgecoaching.com/2010/07/agile culture/

Talaoui, Y., \& Kohtamaki, M. (2020). Of BI research: A tale of two communities. Management Research Review, 43(11). https://doi.org/10.1108/MRR-10-2019-0452

Thomas, D. R. (2006). A General inductive approach for analyzing qualitative evaluation data. American Journal of Evaluation, 27(2), 237-246. http://dx.doi.org/10.1177/1098214005283748 
Zahra, S., Sapienza, H., \& Davidsson, P. (2006). Entrepreneurship and dynamic capabilities: A review, model and research agenda. Journal of Management Studies, 43(4), 917-955. https://doi.org/10.1111/j.1467$\underline{6486.2006 .00616 . x}$

Zimmer, M., Baars, H., \& Kemper, H. (2012). The impact of agility requirements on business intelligence architectures. Proceedings of the 45th Hawaii International Conference on System Sciences, USA, 45, 4189-4198. https://doi.org/10.1109/HICSS.2012.567

\section{AUTHORS}

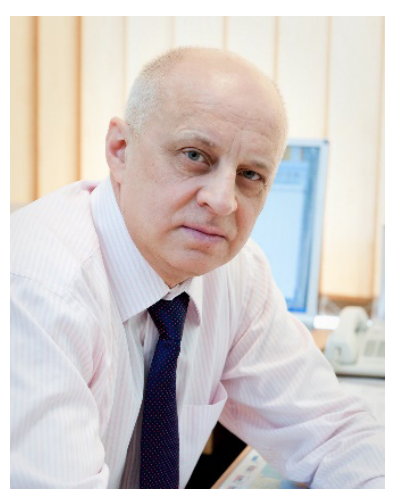

Rimvydas Skyrius is a Professor and head of the Economic Informatics department at the University of Vilnius, Lithuania. He received his doctorate in Operations Research and Computer Applications from ASUMoscow Institute in 1986, and his Master's degree from the University of Vilnius in 1978. His principal research areas are IT-based decision support in business and management, business intelligence and management information needs, and he has published several monographs, a number of articles and conference papers on the subject, as well as co-authored several textbooks in the field.

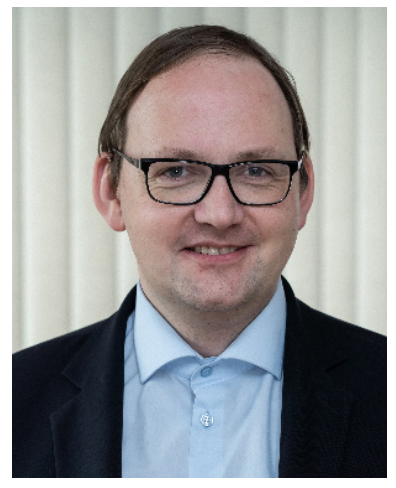

Mindaugas Krutinis is an associate professor at the Department of Economics Informatics, Faculty of Economics and Business Administration, Vilnius University, Lithuania. He received his PhD degree in Civil Engineering from Vilnius Gediminas Technical University (Vilnius'Tech). His current research interests include machine learning technologies and agility in business.

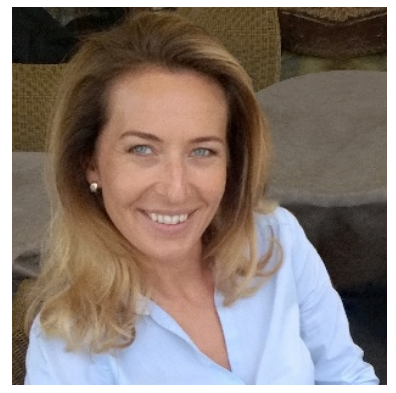

Svetlana Nemitko is a lecturer and a researcher with the Department of Economic Informatics, Faculty of Economics at Vilnius university, Lithuania, where she received her $\mathrm{PhD}$. Her research and teaching interests include business intelligence, analysis of BI business requirements and needs, business insight and intelligence culture issues. She has an extensive background in the area of developing and implementing information systems in business. 


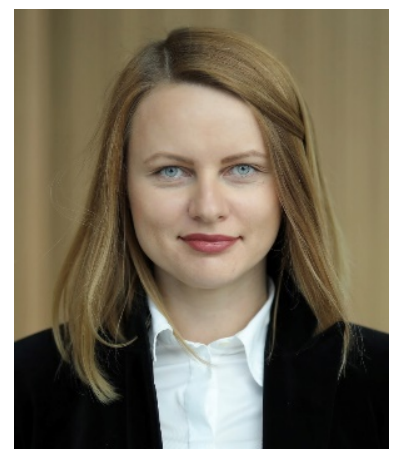

Justina Valentukevičè is a doctoral student at Vilnius University. Her research focuses on the role of Business Intelligence \& Analytics technologies in achieving organizational agility and resilience. Justina is also a professional with versatile background in IT area, including development, implementations and support of business intelligence systems.

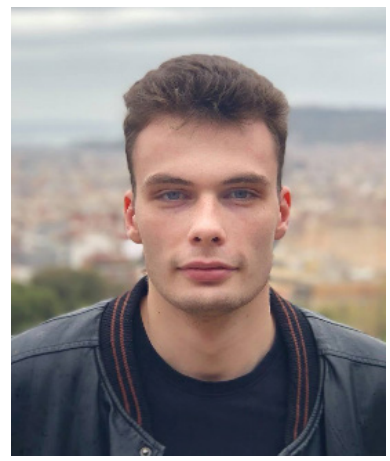

Norbert Andžej Gulbinovič is a master's student with the Department of Economic Informatics, Faculty of Economics and Business Administration at Vilnius University, Lithuania. He is a data-driven person and his interests include Data Analytics, Business intelligence, and Information systems strategies.

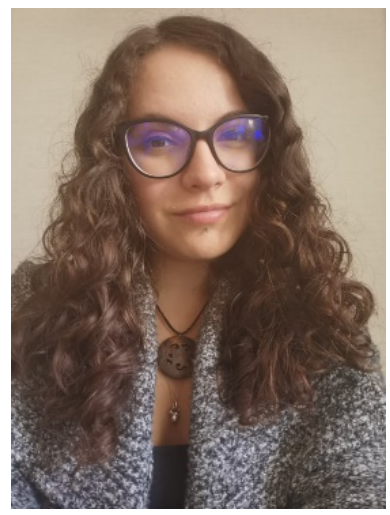

Marija Sanosianaitè is a master's student at the Department of economic informatics, Faculty of Economics at Vilnius University, Lithuania. She got her bachelor's degree in Business Information Management at the Faculty of Communication at Vilnius University, Lithuania. Her research interests include Business intelligence and Business analytics agility with working experience in data analytics and regulatory reporting. 